\title{
Experimental Study of the Use of Phase Change Materials as Cooling Media on Photovoltaic Panels
}

\author{
Razali Thaib, Hamdani Umar, and T. Azuar Rizal
}

\begin{abstract}
Building Integrated Photovoltaics (BIPV) is a combination of electrical technology from photovoltaic solar panels (PV) with building construction. The PV panel was mounted onto the frames attached to the building's main outer wall. When solar radiation energy comes into contact on the PV surface, some part is reflected in the surroundings while mostly absorbed in the PV panel. The energy absorbed is converted into electricity while the rest dissipates into thermal energy, which increases the surface temperature of PV. The increases in the panels' surface temperature negatively impact the electrical output and PV panels' long-term reliability. One of them is the use of phase change materials (PCM) as heat storage materials. This research also emphasizes the use of beeswax as a material for storing heat energy. Using the T-History method by fusing beeswax, show that the temperature range between 49,40 to $57.15^{\circ} \mathrm{C}$ with latent enthalpy $151.65 \mathrm{~kJ} / \mathrm{kg}$. In this research, we tested the use of PCM as a heat storage material for PV panels. Two types of containers to accommodate PCM are used, triangular containers and semicircular containers. From the test results, it was found that beeswax can function well as a heat storage so that the surface temperature of the PV + PCM panel is lower than that of standard PV. So that the voltage generated is higher than standard PV panels.
\end{abstract}

Index Terms - phase change material, beeswax, panel PV, heat storage.

\section{INTRODUCTION}

Renewable energy continues to be a larger part of the global energy mix, particularly in the electricity supply sector. The growth rate in renewable energy use in the last decade has reached double digits and is likely to continue to grow until 2035. The growth is considered only in the utilization of renewable energy for electricity supply, heat energy supply, and energy in the transportation sector [1].

The development of electricity from photovoltaic (PV) solar panel installations varies with the solar radiation level they receive. Geographically, the solar radiation in the blood of tropists is higher than that of wind energy, so the daily and seasonal PV panel power output is expected to be quite good, where on sunny days, the solar radiation has a bell pattern, maximum per midday. However, so far, the PV panel's energy conversion efficiency likely ranges between $10 \%$ to $20 \%$. The last ten years have brought critical technological advances in PV panel technology. Manufacturing of PV panels in the presence of significant cost reductions with thinfilm technology for PV materials, which is gaining a growing market share and bringing the further potential for cost reduction [1].

Submitted on March 20, 2021

Published on April 12, 2021.

Razali Thaib

(e-mail: razalithaib ${ }^{@}$ unsyiah.ac.id)
Photovoltaic is an active solar system that produces electrical energy. The photovoltaic effect is the fundamental process by which photovoltaic converts sunlight into electricity. In this case, the photovoltaic cell is more specifically taking energy from sunlight as the primary energy source taken freely, cleanly, and without a sound. Building integrated photovoltaic (BIPV) is a combination of electrical technology from photovoltaic solar panels and building construction. PV panels surround the building's outer shell with the construction attached to the building's main structure. Several principles that affect integrated photovoltaic include spatial layout and orientation, mass and shape, and building structure of BIPV [2].

According to [2] PV applications for buildings began to appear in the United States and elsewhere in the 1970s. Aluminum-framed PV panels cover the buildings in remote areas, usually places without access to an electric grid. In the 1980s, PV panels began to appear on the roofs of buildings. These PV systems are typically installed in grid-connected utility buildings in areas with centralized power plants. In the 1990s, BIPV development began with a unique construction designed and integrates into building walls. In the last decade, many countries have started building BIPV system projects on new buildings or renovated buildings. This approach proves that BIPV is an effective energy supply technology for the building sector in residential, commercial, and industrial buildings. BIPV systems operate as multifunctional building materials, and therefore the design and installation must perform more than one function. For example, installing a BIPV system on a building's walls can serve as an integral component of the building envelope, the solar energy system that generates electricity for the building, and the lighting element [3]-[8].

The solar energy conversion efficiency of PV panels depends on three factors, the intensity of solar radiation, solar cell material, and operating temperature. In general, solar radiation availability, as a natural resource, is not under human control. The solar cell operates basically on semiconductors' ability to convert sunlight (photons) into electricity by using the photovoltaic effect. Only a small part of the absorbed solar radiation is converted into electrical energy radiation, while the rest converts into heat.

However, with current technology, only $15-20 \%$ of the solar energy received in PV panels can be converted to electricity, with the remaining energy being converted into heat. This heat is then absorbed by the PV device itself, causing the working temperature to reach $80{ }^{\circ} \mathrm{C}$. On the other hand, the conversion efficiency of PV panels decreased 0.4-

Hamdani Umar

(e-mail: hamdani@unsyiah.ac.id)

T. Azuar Rizal

(e-mail: azuarrizal@unsam.ac.id) 
$0.65 \%$ for every degree of increase in PV surface temperature [5]. This phenomenon shows that PV panels' surface temperature regulation is crucial to obtain optimal electrical efficiency, including integrating into the building.

As described above, the thermal energy regulation of the PV system is essential. The heat causes an increase in the module's surface temperature, which affects the PV panel's performance and, in the long run, can also cause a decrease in the strength of the PV material. For BIPV systems, part of the heat can be transferred into the building façade and the room, increasing the building's cooling load. One standard method to reduce excessive temperature rise on PV panels' surface is to absorb heat energy using a swift cooling mechanism. In recent years, considerable research has been done to check and regulate the surface temperature of PV panels.

The main objective of thermal regulation is to maintain the PV's surface temperature at its design conditions. PV/thermal (PV/T) technology was developed to increase the output power of PV panels. In a PV/T system, the PV panel and heat extraction components are integrated into a single PV module [9].

Recently a PCM-based method for cooling PV panels has attracted much attention from researchers. The PV-PCM system is a hybrid technology integrating PV and PCM panels into a single PV panel to increase the higher solar energy conversion efficiency. PCM can absorb heat in the form of latent heat, followed by a change in the solid-liquid phase over a nearly constant temperature range and dissipates the heat as desired [10].

The PV-PCM system consists of a PV panel and a container filled with PCM. The PV panel is attached to the housing's front plate, the back of which is made of a material that can better transfer the conductive heat. Polystyrene is used as an insulating container. PV panels receive solar radiation energy and convert some parts into electricity, while the rest of the radiation energy is converted into heat, then transferred to the PCM container. At the back of the PCM housing, an air cavity is created between the container and the building walls to allow heat dissipated by natural convection.

Much literature describes PCM application as a material for storing heat energy [4], [10]-[14]. Hasan et al. [13] reviewed the use of several PCM candidates in BIPV systems as surface temperature controllers for PV panels. The PCM selection criteria are also suitable for BIPV systems, including melting temperature, latent heat, thermal conductivity, and different configuration designs for PVPCM integration. This study also evaluated the characterization of organic, inorganic, and eutectic PCM applications on PV panels and a study of the effect of using five PCM candidates on PV surface temperature regulation and PV panel performance using three types of insulating materials. The study using the T-History method found that the five PCM candidates' material melting temperature ranged from $21-30{ }^{\circ} \mathrm{C}$, and the latent heat of melting was between $170-240 \mathrm{~kJ} / \mathrm{kg}$. This study also found that some PCMs could potentially not extract latent heat during the removal process due to the low compaction temperature, while the eutectics from fatty acids, such as Capric-Lauric and Capric-Palmitic, showed a decent performance.
The description above concluded that the use of PCM in the BPIV system still requires further study in (i) PCM selection, (ii) mathematical modeling to obtain information about ongoing heat transfer, and (iii) PV-PCM performance testing on the BPIV system on outdoor conditions.

\section{MATERIAl AND METHODS}

The literature review on the subject of thermophysical properties of commonly used PCM, namely, paraffin, salt hydrate, fatty acid, and a mixture of salt and paraffin hydrates, has been conducted. In this study, a novel PCM material has been proposed as a surface temperature control for PV panels in the BPIV system. It has a melting temperature between 43 $51{ }^{\circ} \mathrm{C}$, which is $47 \pm 4{ }^{\circ} \mathrm{C}$, with the latent heat of fusion $>130 \mathrm{~J} / \mathrm{g}$ [10]. The melting temperature value was selected because, in this study, the PV panel used was a NOCT (Nominal operational Cell Temperature $47^{\circ} \mathrm{C}$ ). Moreover, the ambient temperature in Aceh Province ranges from 28 $32{ }^{\circ} \mathrm{C}$. Determination of PCM's thermophysical properties selected as PCM candidates in the BIPV system was carried out using the temperature history method (THM).

Yinping et al. [15] introduced a THM approach to recording the PCM temperature when it cools from a higher temperature liquid-state to a lower temperature solid-state through solidification. The cooling curve derived from the record is then used to determine the start and end of solidification, specific heat capacity, latent heat released during freezing. The method assumes that the supercooling rate represents the end of the melt and does not contain sensible heat due to mismatch, the latter occurring in real fusion/compaction contributing to errors in determining thermophysical properties.

Developing the PCM characteristics using the T-History method, therefore, $25 \mathrm{~g}$ of the PCM sample was placed in a $15 \mathrm{~cm}$ glass test tube with an internal diameter of $1 \mathrm{~cm}$ and a wall thickness of $0.8 \mathrm{~mm}$. These dimensions were chosen to ensure that the Biot number, $\mathrm{Bi}=\mathrm{hR} / 2 \mathrm{k}$, is $<0.1$, where $h$ is the convective heat transfer coefficient, $R$ is the tube's radius, and $k$ is the thermal conductivity of the tube material.

This condition allows heat transfer to occur in only onedimensional conduction along the tube containing the PCM so that the tube can be considered a centralized heating or cooling system, and the centralized capacitance method can be applied.

The PCM and reference (distilled water with a known specific heat capacity) in the tube were heated to a temperature that was increased to above $40{ }^{\circ} \mathrm{C}$, then maintained at this temperature for 2 hours until the PCM had completely melted then cooled at room temperature conditions. PCM temperature and reference water temperature were recorded during the cooling process. The amount of specific heat capacity, latent heat, and heat transfer coefficient was obtained by the simple energy equation proposed by Yinping et al. 

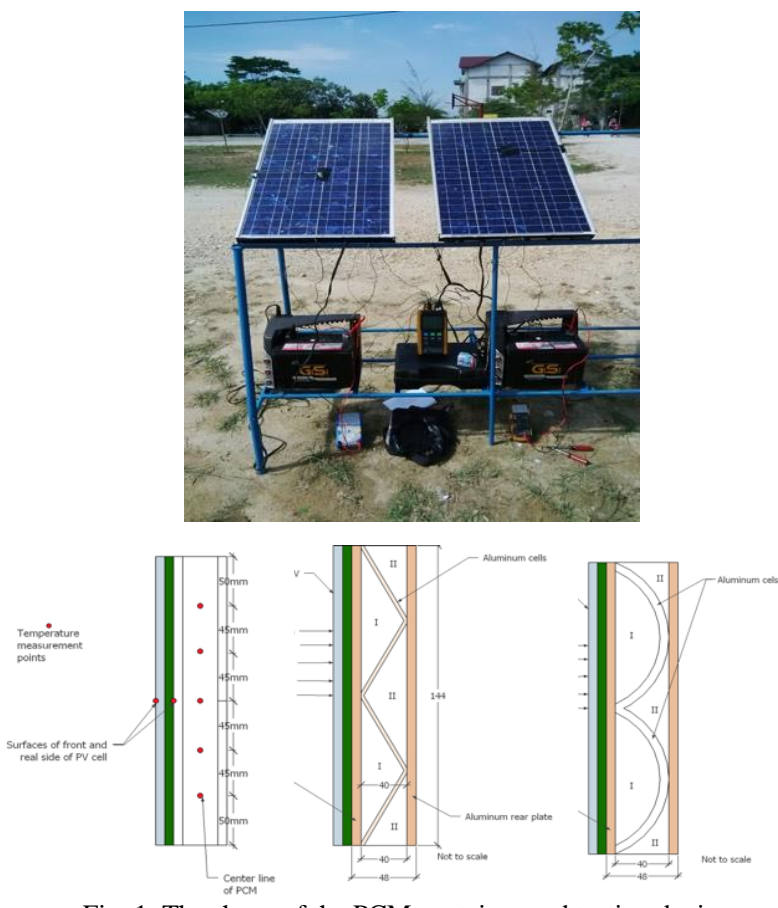

Fig. 1. The shape of the PCM container and testing device.

The primary purpose of adding PCM to PV panels is to absorb the PV panels' heat. Deliberately, the solar panels' surface temperature will not reach peak temperatures or stabilize at average temperatures to obtain maximum efficiency.

In this study, the solar panel used is the Type Silicon Nitride Monocrystalline with a length of $839 \mathrm{~mm}$ and a width of $590 \mathrm{~mm}$. The PCM case comprises an aluminum plate with a thickness of $0.4 \mathrm{~mm}$, a width of $500 \mathrm{~mm}$, and $800 \mathrm{~mm}$. In this test, two different containers were used, namely a triangular container and a semi-circular container. The PCM used in each study was $8 \mathrm{~kg}$. The picture of the PV + PCM testing installation can be seen in Fig. 1.

\section{RESULT AND DISCUSSION}

The results of beeswax temperature change measurement during the cooling process are shown in Fig. 2, seen during the cooling process, the temperature rapidly changes from 90.15 to $57,15^{\circ} \mathrm{C}$. Therefore, it can be expressed that in the temperature range, there is sensible heat expansion. Meanwhile, the drop in temperature from 57,15 to $44,9{ }^{\circ} \mathrm{C}$ took place over a more extended period.

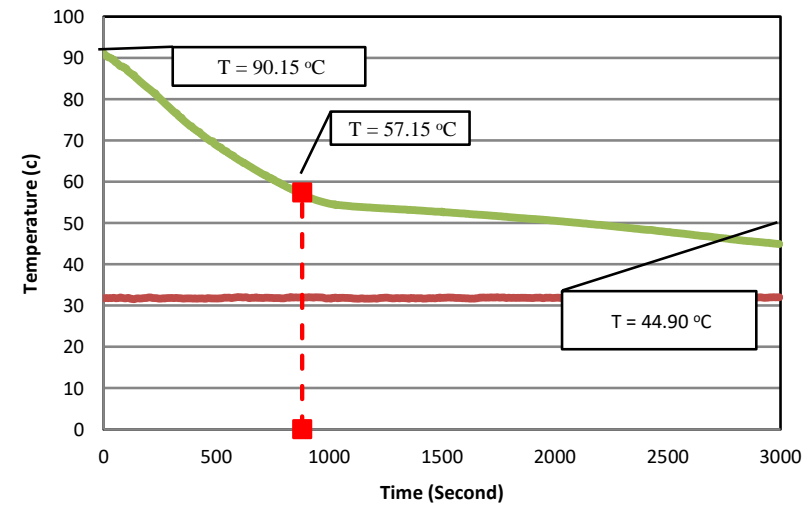

Fig. 2. The test results of beeswax temperature changes using the T_History method.
The freezing or melting temperature $\left(\mathrm{T}_{\mathrm{m} 1}\right.$ and $\left.\mathrm{T}_{\mathrm{m} 2}\right)$ can be determined by analyzing the relationship between changes in temperature $(\Delta T)$ and time $(\mathrm{t})$ below. $\mathrm{T}_{\mathrm{m} 1}$ and $\mathrm{T}_{\mathrm{m} 2}$ can be determined based on $\Delta \mathrm{T}$, which is close to zero or minimal changes, where it indicates the occurrence of a phase change or also referred to as the latent heat loss or absorption process because $\Delta \mathrm{T}$ is almost constant or equal to zero.

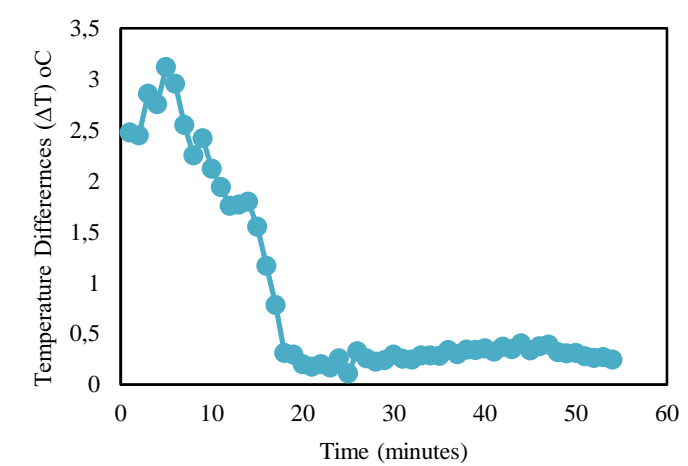

Fig. 3. Temperature change (DT) for determination of beeswax melting temperature.

Fig. 3 shows that the latent heat release process occurs at temperatures of $\mathrm{T}_{\mathrm{m} 1}=57.15{ }^{\circ} \mathrm{C}$ to $\mathrm{T}_{\mathrm{m} 2}=44.90{ }^{\circ} \mathrm{C}$. In this temperature range, the temperature change $(\Delta \mathrm{T})$ is almost constant with a range of 1 to $3{ }^{\circ} \mathrm{C}$. Therefore, it can be stated that the phase change process or the latent heat absorption and release process occurs at that temperature. and it can be determined that the beeswax melting temperature is obtained at $44.9^{\circ} \mathrm{C}$.

This test was conducted to compare the heat absorption results by each PCM. The standard PV PCM as a benchmark is also prepared. Comparisons were made by measuring the upper and lower temperature of the PV's surface and the electric voltage released. The test results using a triangular PCM container are shown in Fig. 3.

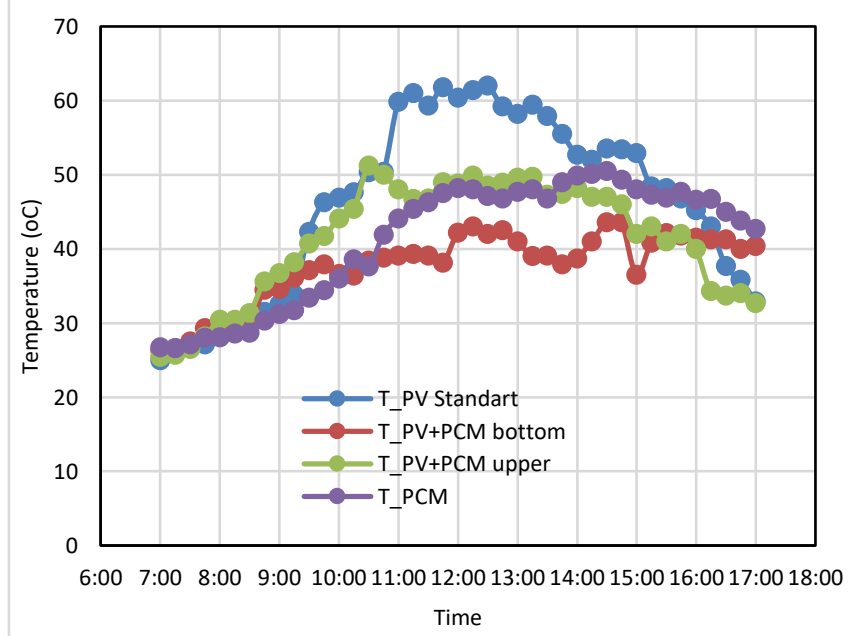

Fig. 4. Temperature measurement results on standard PV panels and PV + PCM panels using a triangular shaped PCM container.

Fig. 4 illustrates the fluctuation of the PV operating temperature reference (T_PVstandar) and T_PV + PCM systems, using a triangular shaped PCM container. 
The increase in the upper surface temperature of standard PV from $26{ }^{\circ} \mathrm{C}$ at 7.00 am to $50.4{ }^{\circ} \mathrm{C}$ at 10.00 am, the temperature increases with a rate of $8.5^{\circ} \mathrm{C} /$ hour. Then the temperature increased rapidly reaching a maximum of $62{ }^{\circ} \mathrm{C}$ at $12.30 \mathrm{pm}$.

The same thing also happened to the upper surface of $\mathrm{PV}+\mathrm{PCM}$ with a slower rate of temperature rise of $6{ }^{\circ} \mathrm{C} /$ hour. However, after $10.00 \mathrm{am}$, the surface temperature of the PV + PCM panel did not tend to increase after reaching a temperature of $49{ }^{\circ} \mathrm{C}$. This shows that there is a cooling process on the panel. Cooling takes place by absorption of heat by the PCM, at which time the PCM temperature has reached its melting temperature. The presence of heat absorption by PCM can also be indicated by the lower surface temperature of the PV+PCM panel than the upper temperature.

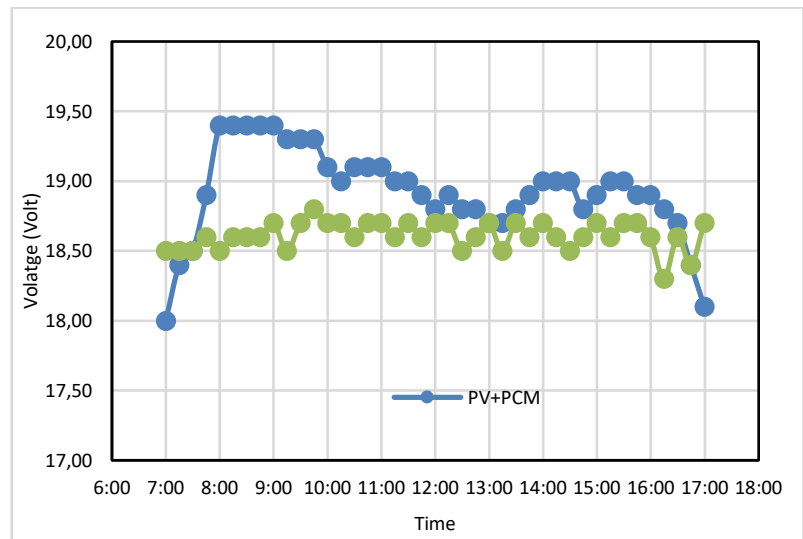

Fig. 5. The results of measuring the output voltage by standard PV and PV + PCM panels using a triangular shaped PCM container.

Fig. 5. shows the results of the measurement of the output voltage by standard PV and PV + PCM panels using a triangular shaped PCM container. From the Figure it can be seen that the PV + PCM panel produces a higher voltage than Standard PV. This shows that the electric power released by $\mathrm{PV}+\mathrm{PCM}$ is higher than Standard PV.

Figure 6 shows the test results using a semi-circular PCM container. In this test, the maximum temperature on the top surface of the PV + PCM panel reached $66.5{ }^{\circ} \mathrm{C}$ at $13: 45$ noon. This temperature is higher than the maximum temperature that occurs in standard PV, which is $62{ }^{\circ} \mathrm{C}$ at 11:00 am. However, in other hours the overall surface temperature of PV + PCM is smaller than standard PV. This also shows that beeswax can function properly as a heat storage material. If a comparison between triangular container and semicircular container is obtained, the average upper surface temperature of the PV + PCM panel using a triangle container is smaller than the semicircular container.

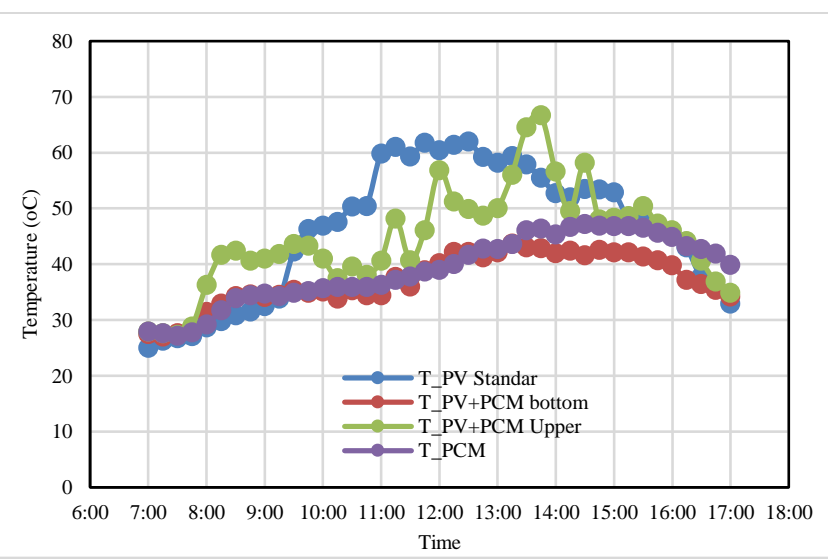

Fig. 6. The results of measuring the output voltage by standard PV and PV + PCM panels using a semicircular PCM container.

\section{CONCLUSION}

In this research, we tested the use of PCM as a heat storage material for PV panels. Beeswax is used as a phase change material which has a higher temperature in the range of 49.40$57.15^{\circ} \mathrm{C}$. Two types of containers to accommodate PCM are used, triangular containers and semicircular containers. From the test results, it was found that beeswax can function well as a heat storage so that the surface temperature of the PV + PCM panel is lower than that of standard PV. So that the voltage generated is higher than standard PV panels.

\section{ACKNOWLEDGMENT}

Thank you to Wahyu Saimanuddin and Muhammad Ismail, undergraduate students of the Department of Mechanical Engineering, Universitas Samudra, who have been involved in data collection.

\section{REFERENCES}

[1] IEA, World Energy Outlook 2013. 2013.

[2] P. Eiffert and G. J. Kiss, Building-Integrated Photovoltaic Designs for Commercial and Institutional Structures A Sourcebook for Architects. 2000.

[3] P. Jayathissa, M. Luzzatto, J. Schmidli, J. Hofer, Z. Nagy, and A. Schlueter, "Optimising building net energy demand with dynamic BIPV shading," Appl. Energy, vol. 202, pp. 726-735, 2017.

[4] R. J. Yang and P. X. W. Zou, "Building integrated photovoltaics (BIPV): Costs, benefits, risks, barriers and improvement strategy," Int. J. Constr. Manag., vol. 16, no. 1, pp. 39-53, 2016.

[5] D. Knera and D. Heim, "Application of a BIPV to cover net energy use of the adjacent office room," Manag. Environ. Qual., vol. 27, no. 6, 2016.

[6] G. Evola and G. Margani, "Renovation of apartment blocks with BIPV: Energy and economic evaluation in temperate climate," Energy Build. vol. 130, pp. 794-810, 2016.

[7] U. Elinwa, M. Radmehr, and J. Ogbeba, "Alternative Energy Solutions Using BIPV in Apartment Buildings of Developing Countries: A Case Study of North Cyprus," Sustainability, vol. 9, no. 8, p. 1414, 2017.

[8] R. A. Agathokleous and S. A. Kalogirou, "Double skin facades (DSF) and building integrated photovoltaics (BIPV): A review of configurations and heat transfer characteristics," Renew. Energy, vol. 89, pp. 743-756, 2016

[9] P. G. Charalambous, G. G. Maidment, S. A. Kalogirou, and K Yiakoumetti, "Photovoltaic thermal (PV/T) collectors: A review," Appl. Therm. Eng., vol. 27, no. 2-3, pp. 275-286, 2007.

[10] T. Ma, H. Yang, Y. Zhang, L. Lu, and X. Wang, "Using phase change materials in photovoltaic systems for thermal regulation and electrical efficiency improvement: A review and outlook," Renew. Sustain. Energy Rev., vol. 43, pp. 1273-1284, 2015.

[11] L. Aelenei, R. Pereira, A. Ferreira, H. Gonçalves, and A. Joyce, "Building Integrated Photovoltaic System with Integral Thermal Storage: A Case Study," Energy Procedia, vol. 58, pp. 172-178, 2014. 
[12] T. Nottingham and N. E. User, "Application of phase change materials as a solution for building overheating : a case for the UK," 2013.

[13] A. Hasan, S. J. McCormack, M. J. Huang, and B. Norton, "Energy and cost saving of a photovoltaic-phase change materials (PV-PCM) System through temperature regulation and performance enhancement of photovoltaics," Energies, vol. 7, no. 3, pp. 1318-1331, 2014.

[14] S. S. Chandel and T. Agarwal, "Review of cooling techniques using phase change materials for enhancing efficiency of photovoltaic power systems," Renew. Sustain. Energy Rev., vol. 73, no. April 2016, pp. 1342-1351, 2017.

[15] Z. Yinping, J. Yi, and J. Yi, "A simple method, the T -history method , of determining the heat of fusion, specific heat and thermal conductivity of phase-change materials," Meas. Sci. Technol., vol. 10, no. 3, pp. 201-205, 1999. 